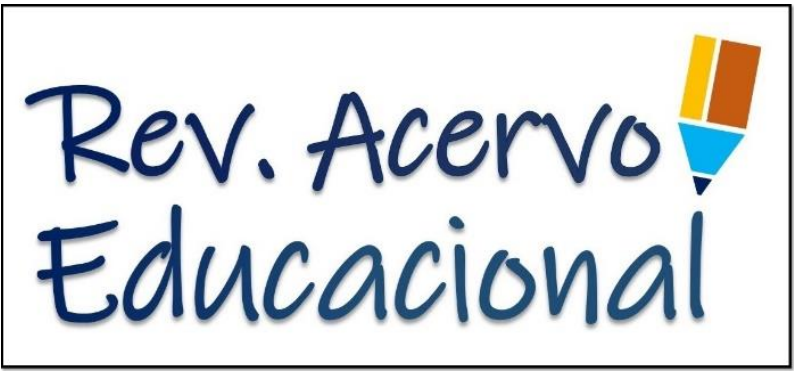

REVISÃo BIBLIOGRÁFICA

Recebido em: 9/2020

Aceito em: $10 / 2020$

Publicado em: 1/2021

\title{
Letrando em tempos de cibercultura: o desafio no processo de alfabetizar
}

\author{
Lettering in cyberculture times: the challenge in literacy process
}

\author{
Letramento en tiempos de cibercultura: el desafío en el proceso de alfabetización
}

Elizabete Ramalho Procópio ${ }^{1 *}$, Anicézia Pereira Romanhol Bette¹, Georgina Maria de Faria Mucci².

\begin{abstract}
Resumo: Este artigo buscou como objetivo, por meio de revisão narrativa, discutir a necessidade de a escola se adequar à geração dos "nativos digitais", no intuito de maximizar a qualidade de ensino, atender as orientações da Base Nacional Comum Curricular (BNCC) e as demandas sociais na contemporaneidade. $O$ percurso metodológico perpassou pela revisão bibliográfica sobre as dissonâncias existentes entre "nativos digitais" e "imigrantes digitais", na realidade educacional, evidenciando as discussões sobre importância da reconfiguração metodológica das práticas de ensino, na escola, através da cibercultura e do ciberespaço. $\mathrm{Na}$ sequência, foi apresentado como esse espaço virtual deve ser usado na fase da alfabetização, conforme os preceitos da Base Nacional Comum Curricular. Ao final dos estudos, percebeu-se que para atender às expectativas dos "nativos digitais", das orientações curriculares atuais e das demandas sociais, as lideranças político-administrativas deverão investir na infraestrutura tecnológica da escola pública, disponibilizando internet contínua e capacitando professores e profissionais da educação. Somado a isso, indispensável se torna a reformulação das metodologias dos educadores para essa transformação, além da parceria das famílias, universidades e da sociedade como um todo.
\end{abstract}

Palavras-chave: Cibercultura, Nativos digitais, Alfabetizar letrando.

\begin{abstract}
This article sought, through a narrative review, to discuss the need for the school to adapt to the generation of "digital natives", in order to maximize the quality of teaching, meet the guidelines of the National Common Curricular Base (BNCC) and social demands in contemporary times. The methodological path went through the bibliographic review on the dissonances existing between "digital natives" and "digital immigrants", in the educational reality, evidencing the discussions about the importance of the methodological reconfiguration of teaching practices, at school, through cyberculture and cyberspace. Then, it was presented how this virtual space should be used in the literacy phase, according to the precepts of the Common National Curricular Base. At the end of the studies, it was realized that to meet the expectations of the "digital natives", the current curricular guidelines and social demands, the political-administrative leaders must invest in the technological infrastructure of the public school, providing continuous internet and training teachers and professionals of education. In addition, it is essential to reformulate the methodologies of educators for this transformation, in addition to the partnership of families, universities and society as a whole.
\end{abstract}

Keywords: Cyberculture, Digital natives, Literate literacy.

1 Universidade do Estado de Minas Gerais (UEMG), Leopoldina - MG. *E-mail: elizabete.procopio@uemg.br

${ }^{2}$ Faculdades Integradas de Cataguases / Grupo UNIS (FIC / UNIS), Cataguases - MG. 
Resumen: Este artículo buscó, a través de una revisión narrativa, discutir la necesidad de la escuela de adaptarse a la generación de "nativos digitales", con el fin de maximizar la calidad de la enseñanza, cumplir con los lineamientos de la Base Curricular Común Nacional (BNCC) y las demandas sociales. en la época contemporánea. El camino metodológico pasó por la revisión bibliográfica sobre las disonancias existentes entre "nativos digitales" e "inmigrantes digitales", en la realidad educativa, evidenciando las discusiones sobre la importancia de la reconfiguración metodológica de las prácticas docentes, en la escuela, a través de la cibercultura y el ciberespacio. Luego, se presentó cómo se debe utilizar este espacio virtual en la fase de alfabetización, de acuerdo con los preceptos de la Base Curricular Nacional Común. Al finalizar los estudios, se percató que para cumplir con las expectativas de los "nativos digitales", los lineamientos curriculares vigentes y las demandas sociales, los líderes político-administrativos deben invertir en la infraestructura tecnológica de la escuela pública, brindando internet continuo y capacitando a docentes y profesionales. de Educación. Además, la reformulación de las metodologías de los educadores para esta transformación es indispensable, además de la alianza de familias, universidades y sociedad en su conjunto.

Palabras clave: Cibercultura, Nativos digitales, Alfabetización alfabetizada.

\section{INTRODUÇÃO}

O mundo contemporâneo é marcado por inúmeras possibilidades de comunicação, inaugurando novas formas de socialização e interação tão diversas quanto as tecnologias que as tornam possíveis (GIARETTA JBZ e GIULIO GMD, 2018). É preciso considerar que as gerações atuais e as próximas estarão completamente imersas nessa realidade, sendo necessárias discussões e compreensão das possibilidades de utilização dessas novas formas de comunicação, advindas desse processo (WADY JRMC e DELGADO OC, 2018).

As Tecnologias da Informação e Comunicação (TIC), fruto da revolução informacional Castells MI (2009), permitem a comunicação em rede, adentrando variados espaços, inclusive o escolar. Mesmo distantes fisicamente, os indivíduos podem encontrar-se, virtualmente, não só estabelecendo diálogo, mas também adquirindo informações e aprendizados. Esse amplo conjunto de informações/conhecimentos/linguagens ofertado vem propiciando aos usuários diferentes formas de uso e ritmos de ação (BERNAL ML, et al., 2019).

Mcluhan M (2007) aborda os meios de comunicação como extensões do homem, assim, cada nova tecnologia comunicacional se relaciona com a sociedade que a desenvolve e utiliza, podendo transformá-la ou aprisioná-la ao passado e, ou gerando uma dinâmica própria e orgânica entre tecnologias e sociedades.

Entendida como um espaço de troca informativa, a escola não é mais um local onde o professor é detentor do saber e o aluno aquele sem nenhuma bagagem informacional. Por meio das trocas comunicacionais tecnológicas, mais do que nunca, o modelo de educação monológico e unívoco parece perder seu espaço. Indo de encontro a Moran JM (2000), acredita-se que diante das transformações causadas pelas TIC, na sociedade, torna-se necessário a integração dos meios tecnológicos na escola. Segundo Moran JM (2000), o computador e as ferramentas a ele relacionadas são poderosos recursos, com velocidade, programas e comunicação capazes de redescobrir novos conceitos, lugares e ideias. Se, à disposição da escola, seja no ensino presencial ou à distância, constituem-se como importantes mecanismos de interação entre professores e alunos, para realização de fóruns, aulas online, chats, blogs e leitura de hipertextos. Mediante os diversos canais de comunicação e seus usos, as informações vão circulando, ininterruptamente, no meio social, influenciando o contexto escolar.

Esse contexto sinaliza a necessidade de a Educação Brasileira direcionar suas pesquisas e discussões para a implementação e uso das TIC, no meio escolar, a fim de que os alunos vivenciem os diferentes mecanismos de comunicação e informação virtuais, bem como suas estratégias de uso. Mais interessante se torna iniciar essa tarefa, nos primeiros anos, do Ensino Fundamental, anos iniciais, quando a criança está na fase da alfabetização, para que o papel não seja o único suporte de desenvolvimento de aprendizagem da leitura e da escrita. Vale salientar que as ferramentas digitais, por disponibilizarem atividades lúdicas e 
interativas, atraem as crianças, motivando-as ao estudo. Além disso, a escola que viabiliza o uso dos recursos tecnológicos propicia ao professor e aluno integrarem o espaço escolar com os espaços virtuais, dentro e fora da sala de aula (GLORIA JS e FRADE ICAS, 2015).

Este trabalho intencionou apresentar através de uma revisão narrativa sobre os desafios da escola e do professor em utilizar a cibercultura e o ciberespaço como ferramentas para a alfabetização e o letramento, nos anos iniciais do Ensino Fundamental, com base na geração dos "nativos digitais" e na proposta do documento educacional vigente, isto é, a Base Nacional Comum Curricular (BNCC), cujo processo de implementação, nas instituições escolares, deverá ocorrer neste ano de 2020. Evidenciará, também, 0 paradigma histórico-cultural, como um alicerce teórico para a compreensão da sociedade da informação e suas consequências no desenvolvimento humano. Para tanto, esta pesquisa utilizará de arcabouço teórico relacionado à literatura e legislações pertinentes.

\section{REVISÃO BIBLIOGRÁFICA}

\section{Os nativos digitais, os imigrantes digitais e as TIC no contexto educacional}

McLuhan M (2007) já previa que a evolução das tecnologias iria transformar os relacionamentos humanos. Assim ocorreu, quando a sociedade industrial cedeu espaço aos avanços tecnológicos e, consequentemente, à sociedade da informação, que alterou o percurso comportamental e cultural das novas gerações (FEY AF, 2011; GIACOMETTI ER e MILL D, 2017).

No Brasil e no mundo, salvo as exceções, devido às desigualdades socioeconômicas, as crianças e os jovens da atualidade vivem cercados de tecnologias e conectados à internet, utilizando telefones celulares, computadores, tablets, dentre outros. Eles nasceram depois da década de 1980, já predispostas ao uso dessas tecnologias e aptos a realizarem múltiplas tarefas simultaneamente (PALFREY J e GASSER U, 2011).

O pesquisador, escritor, consultor e criador de site, relacionado à criação de jogos, Prensky M (2001), denominou-as como "nativos digitais", por terem nascido e crescido, na época em que a rede de computadores e os artefatos tecnológicos já estavam disponíveis à sua geração.

Para melhor caracterizá-los, Franco CP (2013) elencou alguns de seus comportamentos, como estarem on-line constantemente e sentirem-se confortáveis nesses espaços; utilizarem das tecnologias digitais para a busca de informações, para a comunicação com os amigos (e os desconhecidos também) nas redes sociais; bem como para compartilharem fotos e vídeos. Tanto emitem, quanto recebem e processam as informações de modo muito rápido.

Isso demonstra a singularidade no modo de aprenderem, uma vez que possuem experiências mais ativas, sendo proficientes em realizarem várias ações, simultaneamente, por utilizarem das tecnologias da comunicação que os auxiliam nesse aspecto (SANTOS LS, 2011).

Além dos "nativos digitais", Prensky M (2001) denominou, também, os “imigrantes digitais", isto é, aqueles que não pertencem a era do mundo digital, contudo, em algum momento da vida, desenvolveram o aprendizado para o uso de determinados recursos tecnológicos. São as gerações anteriores à dos "nativos digitais", que se esforçaram ou esforçam para conquistarem as habilidades digitais, buscando as devidas adaptações, porém, mantendo, como os imigrantes, um certo "sotaque", que se relaciona com o seu passado. (WADY JRMC e DELGADO OC, 2018).

Enquanto os "nativos digitais" utilizam o próprio programa, por meio da internet, para saberem como utilizálo, os "imigrantes digitais" irão ler um manual para a compreensão de uso desse programa. Outro "sotaque" muito comum é o quando o "imigrante digital", ao invés de enviar a URL (endereço do site) para alguém, convida a pessoa para ver o website no ambiente físico. Essas diferenças de ações entre "nativos digitais" e "imigrantes digitais" podem ser impactantes para ambos, uma vez que, de certa forma a linguagem usada é distinta. Os mais velhos ainda estão usando uma linguagem da era pré-digital, sendo que os mais novos a utilizam numa perspectiva totalmente nova (PRENSKY M, 2001). 
Esse é um dos grandes desafios no processo de ensino e aprendizagem dos alunos no meio escolar, pois que os educadores parecem os mesmos, mas os estudantes, não (WADY JRMC e DELGADO OC, 2018). Os professores "imigrantes digitais" ainda persistem em ensinar, vagarosamente, com aulas totalmente expositivas, e com metodologias que não atraem os "nativos digitais". Estes, por sua vez, frequentemente, têm como ponto de vista que seus professores não os instigam a focar nas aulas (PRENSKY M, 2001).

Para que as escolas estejam em consonância com os alunos de hoje, terão que superar a forma tradicional de trabalhar igualmente com todos os alunos, sem observar que cada qual tem uma maneira singular para assimilar e aprender (MORAN JM, 2015).

Se o mundo e suas relações mudaram, a escola também precisa fazê-lo (KENSKI VM, 2012). Diante dos novos contextos de comunicação, emergem-se o ciberespaço também chamado de rede e a cibercultura que se refere ao conjunto de práticas, técnicas, atitudes e valores que se desenvolve com o crescimento do ciberespaço (sugerindo à instituição educacional e ao professor uma consciência de sua função e de seu preparo frente ao processo de mediação das informações (LEVY P, 1999).

Para a compreensão da sociedade da informação e suas consequências no desenvolvimento humano, o paradigma histórico-cultural, por meio de Vygotsky LS (1998), esclarece que diferente dos animais que estão inteiramente sujeitos aos mecanismos instintivos de adaptação, o homem criou instrumentos e signos que lhe permitem intervir, transformar e conhecer o mundo. De acordo com Vygotsky LS (op. cit.), os instrumentos e os signos estabelecem uma relação do homem com a realidade, sendo construções da inteligência humana. Dentre os sistemas de signos humanos, destaca-se a linguagem, elaborada ao longo da história da humanidade (VYGOTSKY LS,1998).

A criança, ao se relacionar com símbolos e signos que fazem parte da cultura informacional, pode também utilizar destes no processo de aquisição e desenvolvimento da leitura e da escrita. Mesmo sem ainda decodificar os signos linguísticos, é possível que essa criança consiga buscar uma música no celular, interagindo com o equipamento. Se essa interação for planejada e mediada por um adulto, pais ou professores, certamente, poderá se tornar, além de entretenimento, um recurso educativo.

A existência de um ciberespaço e de uma cibercultura fará com que a difusão informativa e a troca comunicacional atinjam níveis imensuráveis, permitindo empoderamento aos usuários, mas isso promoverá a emancipação, quando for mediado por valores e compromissos éticos (NEJM R, 2012). Em meio a tais mídias eletrônicas, as crianças poderão ter dificuldades de discernimento e ficarem confusas entre a vida privada e a pública, e, entre o mundo infantil e o adulto. Necessitarão, portanto, de reflexões, provocadas e mediadas por um adulto (BELLONI ML, 2007). Em âmbito escolar, será necessário que o docente leve em consideração as práticas pedagógicas inovadoras, que abram espaço para o professor do saber em detrimento do professor de informação que somente acumula saberes, sem analisar, verificar, agrupar para resolver problemas (CHARLOT B, 2019).

Segundo Almeida MEB (2006), o desenvolvimento de atividades, em ambientes virtuais, por meio do diálogo, permitirá o encontro com o outro, com suas ideias, possibilitando uma reelaboração de representações expressas pela escrita. Para ela, rompe-se dessa forma a limitação espaço-temporal da aula e de espaços pedagógicos, redimensionando as relações interpessoais. Diante dessa evolução tecnológica, a instituição escolar precisa ressignificar sua gestão e interação, suas metodologias de ensino e seus recursos didático-pedagógicos, para não ficar mais defasada do que já se encontra.

O ciberespaço no processo de alfabetizar letrando, segundo a BNCC e o Currículo Referência de Minas Gerais

Alfabetização e letramento, embora possuam suas especificidades, são indissociáveis no processo da aquisição da leitura e da escrita. O vocábulo "letramento", segundo Soares M (2009), deriva-se da língua inglesa, literacy, que se originou do latim littera, cujo significado em português é "letra": Para melhor compreensão, um indivíduo, ao lidar com os textos, na prática social, mesmo sem saber ler e escrever, é considerado letrado (SOARES M, 2009). 
Na atualidade, o vocábulo "letramento" tem sido utilizado no plural como: letramento digital, visual, político, dentre outros Barton D (2000), no sentido de o indivíduo conhecer e saber interagir com determinada linguagem ou assunto.

Para Soares M (2020), embora a alfabetização e o letramento sejam processos cognitivos e linguísticos distintos, tanto no ensino como na aprendizagem de ambos, não se pode negar que esses processos sejam simultâneos e interdependentes. Enquanto a alfabetização é a técnica para a aquisição da escrita, o letramento é o contato com a cultura escrita, para inserção do indivíduo nas práticas sociais e pessoais.

A alfabetização envolve o ensino da técnica de codificação e decodificação do sistema de escrita, das relações fonema/grafema, do uso dos instrumentos com os quais se escreve, associados ao uso e à interpretação do código (SOARES M, 2020).

Segundo Xavier ACS (2005), o fato de o indivíduo ser alfabetizado, isto é, saber decodificar (ler) e codificar (escrever) sinais gráficos no seu idioma não significa que ele esteja apto para utilizar, ativamente, dos textos, na prática social. Isso se deve ao fato de ele não dominar as habilidades de leitura e escrita, pois ao ler, só consegue fazê-lo de forma superficial e sem criticidade, e, ao escrever, só consegue produzir textos simples como bilhetes e listas de compras.

No final de 2017, com o intuito de normatizar e igualar, ao máximo, a oferta das aprendizagens essenciais e progressivas para todos os alunos brasileiros, o Conselho Nacional de Educação aprovou a Base Nacional Comum Curricular, cujo documento balizou a construção dos currículos de educação básica brasileira (BRASIL, 2017). Na parte introdutória da BNCC, alinhada à Agenda 2030 da Organização das Nações Unidas (ONU) (BRASIL, 2017), consta que a educação, ao desenvolver e incentivar seu educando certos valores, este transformará a sociedade, humanizando-a e promovendo condições para cuidar do meio ambiente (BRASIL, 2017).

Com relação ao trabalho com as linguagens, no cotidiano escolar, esse documento propõe diferentes modalidades como a verbal (oral e escrita), visual e motora (Libras), sonora, artísticas, digital, dentre outras. No que se refere à linguagem digital, o aluno deve compreender e utilizar as tecnologias digitais de informação e comunicação de maneira crítica, significativa, reflexiva e ética, tanto nas práticas escolares, como nas sociais. $\mathrm{O}$ intuito é que o estudante aprenda a usá-las para expressar-se e comunicar-se nos mais variados contextos sociais, exercendo o protagonismo na vida pessoal e coletiva (BNCC, 2017).

O início do processo de implementação da BNCC nas escolas de educação básica brasileira foi previsto para o ano de 2020. Devido às especificidades econômicas, geográficas e culturais de cada estado brasileiro e do Distrito Federal, estes deveriam construir o seu Currículo Referência, tendo em vista o "arcabouço legal, conceitual e material", inseridos na Base Nacional Comum Curricular. Nessa perspectiva, foi elaborado o Currículo Referência de Minas Gerais (MINAS GERAIS, 2018). O componente curricular de Língua Portuguesa desse documento apresenta a linguagem como objeto de ensino, que servirá, exponencialmente, para que os sujeitos aprendam a construir sentidos nos textos que leem, ao interagir com seus pares (MINAS GERAIS, 2018).

Sobre os textos digitais, estes são diferentes, em diversos aspectos, dos textos impressos, uma vez que o suporte dos primeiros é a tela do computador ou dos dispositivos móveis, como o celular e tablets. Também os modos de ler e escrever se distinguem, devido à linguagem híbrida entre códigos, palavras e imagens, sendo necessário que o professor trabalhe com as crianças, simultaneamente, a alfabetização, o letramento e o letramento digital (XAVIER ACS, 2005).

Amante L (2011) considera que que as atividades desenvolvidas a partir das tecnologias propiciarão oportunidades educativas ao educando, se estiverem atreladas ao seu sentido de uso e para que a globalidade dos objetivos curriculares seja atingida, é importante que professor alfabetizador selecione a tecnologia correta e as ferramentas adequadas, contextualizadas à realidade social de seus alunos. Com relação aos dois primeiros anos dos Anos Iniciais do Ensino Fundamental, o Currículo Referência de Minas Gerais (2018) afirma que deverão ser dedicados ao desenvolvimento de alfabetizar letrando, isto é, o aluno irá aprender ler e escrever por meio dos textos existentes, para que haja sentido para ele. 
Dentre as práticas de letramento, evidencia a importância de o professor alfabetizador trabalhar com a sua classe o letramento multimodal, que implica levar os estudantes a desenvolverem habilidades que se relacionem à manipulação das diversas tecnologias comunicativas, interagindo e conhecendo a função dos diversos recursos semióticos e a sua utilização integrada na construção dos sentidos textuais (MINAS GERAIS, 2018). Para tanto, o professor alfabetizador poderá planejar aulas que estimulem as crianças estarem em contato com os hipertextos na rede digital que é composta de textos não lineares e que oferecem caminhos para outros textos, imagens ou vídeos que poderão ser estimulantes para o processo de alfabetização. (COSCARELLI CV, 2009).

Como as crianças matriculadas no primeiro ano dos Anos Iniciais do Ensino Fundamental estão apenas com seis anos de idade, torna-se indispensável atentar-se para as especificidades da infância, envolvendo, portanto, no desenvolvimento da aprendizagem, o uso dos jogos e da ludicidade como perspectiva formativa (MINAS GERAIS, 2018).

Para alfabetizar num contexto de letramento, nos dois primeiros anos do Ensino Fundamental (Anos Iniciais), o Currículo Referência de Minas Gerais (2018) propõe práticas de leitura e escrita, divididas em quatro campos de atuação, a saber: Campo da vida cotidiana, Campo artístico-literário, Campo da vida pública e Campo das práticas de estudo e pesquisa. O campo da vida cotidiana envolve textos como parlendas, quadra, quadrinhas, trava-línguas, canções e cantigas; no da vida pública, há os slogans, peça de campanha de conscientização destinada ao público infantil, notícias curtas para o público infantil e jornal falado; já o campo das práticas de estudo e pesquisa sugere textos como entrevistas e curiosidades; e, para finalizar, o campo artístico literário propõe textos literários de variados gêneros. Para que tais campos sejam desenvolvidos, por meio do ciberespaço, na instituição escolar, conforme propõe a BNCC (2017) e o Currículo Referência (2018), o professor alfabetizador, deverá promover, simultaneamente, práticas pedagógicas que insiram as tecnologias, o ciberespaço e a cibercultura.

\section{CONSIDERAÇÕES FINAIS}

Com base nos estudos realizados, observou-se que se a escola não for condizente com as expectativas dos "nativos digitais", é bem provável que os alunos perderão o interesse pelas aulas, permanecendo sem foco, o que poderá gerar a indisciplina na sala de aula. Automaticamente, a qualidade do ensino e da aprendizagem ficará comprometida. Os "nativos digitais" utilizam dos meios tecnológicos digitais com tamanha facilidade e rapidez. Navegam em diversos sites, pesquisam temas de seu interesse e conversam, concomitantemente, com seus amigos virtuais. Isso sinaliza o seu perfil protagonista e a sua característica mais evidente, ser multitarefas. No processo de alfabetizar letrando, nos anos iniciais do Ensino Fundamental, o professor alfabetizador selecionará ferramentas digitais que propiciarão aos alunos desenvolver aprendizagens de leitura e escrita, conforme direciona a BNCC. Assim, torna-se indispensável que os professores redimensionem suas práticas pedagógicas, adequando metodologias de ensino, relacionadas ao ciberespaço e à cibercultura, inserindo o aluno como o protagonista de seu processo de aprendizagem.

\section{REFERÊNCIAS}

1. ALMEIDA MEB. Educação, ambientes virtuais e interatividade. In SILVA M. Educação online. São Paulo: Loyola, 2006.

2. AMANTE L. As tecnologias Digitais na escola e na Educação Infantil. In: TIC e emergência da Linguagem Escrita. Pinhais: Editora Melo, 2011.

3. BARTON D, HAMILTON M. Literacy Practices. In: BARTON D, et al. Situated literacies: reading and writing in context. New York: Routledge, 2000, p. 7- 15.

4. BELLONI ML. Infância, mídias e educação: revisitando o conceito de socialização. Revista Perspectiva. Florianópolis, 2007; 25 (1), 57-82.

5. BERNAL ML, et al. As tecnologias da relação, informação e comunicação (TRIC) como ferramentas de inclusão social. Interface (Botucatu), Botucatu, 2019; 23.

6. BRASIL. Base Nacional Comum Curricular. Brasília: MEC, 2017.

7. CASTELLS MI. A sociedade em rede (a era da informação: economia, sociedade e cultura. V.1. rev. amp. São Paulo: Paz e Terra, 2009. 
8. CHARLOT B. A questão antropológica na Educação quando o tempo da barbárie está de volta. Educar em Revista, Curitiba, Brasil, 2019; 35 (73),161-180.

9. COSCARELLI CV. Textos e hipertextos: procurando o equilíbrio. Linguagem em (Dis)curso, Palhoça, SC, 2009; 9(3): 549-564.

10. EDUCA, IBGE. Uso de internet, televisão e celular no Brasil. 2018.

11. FEY AF. A linguagem na interação professor-aluno na era digital: considerações teóricas. Revista Tecnologias na Educação, 2011; 3 (1).

12. FRANCO CP. Compreendendo as experiências de aprendizado dos nativos digitais. Revista Brasileira de Linguística Aplicada, Belo Horizonte, 2013; 13, (3): 643-658.

13. GIACOMETTI-ROCHA E, MILL D. Mudanças nas interações sociais e mobilidade na educação com a mediação das Tecnologias Digitais de Informação e Comunicação. Revista Ibero-Americana de Estudos em Educação, Araraquara, 2017; 12 (2), 966-982.

14. GIARETTA JBZr, GIULIO GMD. O papel das tecnologias de comunicação e informação (TIC) no urbano do século XXI e na emergência dos novos movimentos sociais: reflexões a partir de experiências na megacidade de São Paulo. Rev. Bras. Estud. Urbanos Reg., São Paulo, 2018; 20 (1), 161-179.

15. GLORIA JS, FRADE ICAS. A alfabetização e sua relação com o uso do computador: o suporte digital como mais um instrumento de ensino-aprendizagem da escrita. Educ.rev., Belo Horizonte, 2015, 31(3),339-358.

16. KENSKI VM. Tecnologias e ensino presencial e a distância. Campinas-SP: Papirus, 2012.

17. LEVY P. Cibercultura. São Paulo: Editora 34, 1999.

18. MCLUHAN M. Os meios de comunicação como extensões do homem. São Paulo: Cultrix, 2007.

19. MINAS GERAIS. Currículo Referência de Minas Gerais. SEE /MG, 2018.

20. MORAN JM. Ensino e aprendizagem inovadores com tecnologias audiovisuais e telemáticas. In: MORA, et al. Novas tecnologias e mediação pedagógica. Campinas, SP: Papirus, 2000; p.11-68.

21. MORAN JM. [Coleção Mídias Contemporâneas. Convergências Midiáticas, Educação e Cidadania: aproximações jovens. Vol. II] Carlos Alberto de Souza e Ofelia Elisa Torres Morales (orgs.). PG: Foca Foto-PROEX/UEPG, 2015.

22. NEJM R. Potencialidades e limites das tecnologias na promoção dos direitos humanos de crianças e adolescentes. In: RIBEIRO JC, et al. Midias sociais: saberes e representações [online]. Salvador: EDUFBA, 2012, pp. 249-269.

23. PALFREY J, GASSER U. Nascidos na era digital: entendendo a primeira geração dos nativos digitais. Porto Alegre: ARTMED, 2011.

24. PRENSKY M. Digital Native, digital immmigrants. Digital Native immigrants. On the horizon, MCB University Press, 2001, 9(5).

25. SANTOS LS. Implicações do status de nativos digitais para a relação entre gerações (professor e aluno) no contexto escolar. In anais V Simpósio Nacional da ABCiber - UDESC/UFSC, 2011.

26. SOARE M. Alfaletrar: toda criança pode aprender a ler e a escrever. São Paulo: Contexto, 2020.

27. SOARES M. Alfabetização e letramento. São Paulo: Contexto, 2009.

28. VYGOTSKY LS. Formação Social da Mente. São Paulo: Martins Fontes, 1998.

29. XAVIER ACS. Letramento Digital e Ensino. In: SANTOS CF, MENDONÇA M (Org.). Alfabetização e Letramento: conceitos e relações. Belo Horizonte: Autêntica, 2005; 1:133-148.

30. WADY JMRC, DELGADO OC. Reflexões acerca da utilização das tecnologias de informação e comunicação (tic) no contexto da educação infantil. Revista Espaço Acadêmico, 2018,8 (2). 